\title{
Comparison of the Thermal Properties of Asbestos and Polyvinylchloride (PVC) Ceiling Sheets
}

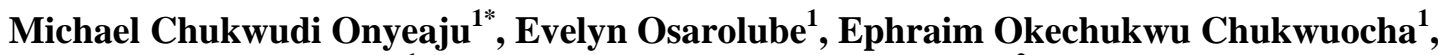 \\ Chinedu Ekuma Ekuma1, Great Arusuedafe Jacob Omasheye ${ }^{2}$ \\ ${ }^{1}$ Department of Physics, University of Port Harcourt, Port Harcourt, Nigeria; ${ }^{2}$ Department of Physics, College of Education Warri, \\ Warri, Nigeria. \\ Email: *omicronics@yahoo.com
}

Received December $30^{\text {th }}, 2011$; revised January $19^{\text {th }}, 2012$; accepted February $26^{\text {th }}, 2012$

\begin{abstract}
This work investigates the thermal properties of polyvinyl chloride and asbestos ceiling sheet. We have studied the thermal properties of these materials in terms of the thermal conductivity (TC), thermal resistivity (TR), thermal diffusivity, thermalabsorptivity, and specific heat capacity (SHC). With the view to establishing their suitability as ceiling materials in building designs for tropical regions. The result showed that thermal conductivity, thermal resistivity, thermal absorptivity, thermal diffusivity and specific heat capacity values of PVC and asbestos ceiling sheets falls within the range of good insulating materials like pine fibre-board and oak wood. With these properties and further improvement, they possess properties that can be harnessed for possible usage as ceiling materials.
\end{abstract}

Keywords: Thermal Conductivity; Heat Capacity; Thermal Absorptivity; Thermal Resistivity

\section{Introduction}

In tropical countries, the greatest thermal gain occurs through the roof of a house. In Nigeria, the use of zincmade roofs without a ceiling is very common. Thus there is intense heat transfer to the internal environment which may cause thermal discomfort to the inhabitants [1]. The design of the building envelope is crucial towards attaining an optimal configuration, which responds effectively to environmental changes in order to reduce their impact. The understanding of energy related characteristics and the evaluation of the relevant properties of the building envelope is an integral part of every environmental assessment. Solar energy affects significantly, the interior environment and the energy requirements of buildings [2].

One way to reduce the heat flux is the use of radiant barriers which reduce the heat flux through radiation. Most building materials particularly, roofing and walling materials are good conductor of heat. Materials like zinc and aluminium are commonly used in the form of sheet metal for rooting and walling in building construction.

The knowledge of thermal properties of different walling material is very important in the choice of the type of material to be used in the construction of a selfcooling or passively cooled building design. This view

\footnotetext{
"Corresponding author.
}

was collaborated in $[1,3]$ in their study of the thermal properties of oil and Raffia palm fibres. The heat flow through any building is dependent on the thermal properties of the material used in the building. Most commonly used African timber species with useful properties for building construction are becoming scarce and are gradually extincting due to deforestation and increasing demand for wood for furniture making, boat construction and fire wood [1]. Such scarcity has resulted in the search for alternative sources of material with suitable building construction properties. Polyvinyl chloride (PVC) and asbestos is one of such materials being studied for this application.

In view of the urgent need to house large number of people throughout the world (especially in Tropic regions) and the rapid expansion in industry and the strenuous efforts being made to provide facilities as economicallyviable and as quickly as possible, some form of interim guidance relating to thermal requirements is urgently needed [1] and the most realistic approach and cost effective is to try to understand the intrinsic properties of these promising materials before experimenting on them. These intrinsic properties are better understood using computational techniques. This is because, theinformation regarding the thermal gain is not clear to manufactures and many of them are only informed of the radiant heat reduction capabilities based on calculations of tabu- 
late demissivity values for the reflective material [3].

Recently in Nigeria, attention has been shifted from the use of asbestos as a means of celling to PVC, the hazardous effect of walling materials especially, theasbestos group of naturally occurring hydrated mineral silicates has been shown to induce fibrosis, lungcancer, mesothelioma, and probably other kinds of intestinal cancer diseases [4].

Thus, our aim in this present study is to compute thermal properties of interest, e.g., SHC, TC, TD, TA, and TR which will enable us to characterize the thermal properties of the selected materials. Our findings will be of utmost importance in any building designs where temperature is of great importance.

\section{Theoretical Framework}

Temperature variations with thickness of solid materialsdepend on the TC, SHC, TA, and diffusivity of the material. These properties determine whether or not the material can be used as a heat conductor or insulator. We can treat the samples under investigation as an ideal one dimensional heat transfer problem. The sample will follow the general time dependent one dimensional heat transfer equation governed by Fourier's law [1,2,5-10],

$$
\frac{\partial^{2} T(x, t)}{\partial x^{2}}=\frac{\rho c}{k} \frac{\partial T(x, t)}{\partial t}
$$

For a semi-infinite, homogeneous solid with constant thermal properties, Equation (1) can be solved when the boundary conditions at the material surface is known on both sides of the wall, and adopting the two boundary conditions [9] in accordance with Newton's law, and also using the initial conditions $(0, t)$, the energy balance equation follows Newton's law at the material surface,

$$
\begin{aligned}
& -k(\partial T(0, t) / \partial x)=h_{e}\left(T_{s a}-T_{e}\right), \\
& -k(\partial T(0, t) / \partial x)=h_{i}\left(T_{i}-T_{i n}\right) .
\end{aligned}
$$

where $h_{e}$ and $h_{i}$ are the heat transfer coefficients on the exterior and the interior surfaces of the wall, respectively, $T_{e}$ and $T_{i}$ correspond to the exterior $(x=0)$ and interior $(x$ $=L$ ) surfacestemperaturesof the wall, respectively. These two equations balance the heat transfer between the interior and exterior of the walling system [9]. The parameter,

$$
T_{s \alpha}=T_{a t m}+\alpha I \in \Delta R
$$

is known as the solar temperature including the heat gain due to solar radiation absorption; $k$ is the thermal conductivity of the material; $T$ is the temperature of the material; $h$ is the heat transfer coefficient at the surface of the material; $T_{a t m}$ is the atmospheric air temperature; $\alpha$ is the solar radiation absorptivity at the surface; $I$ is the intensity of solar radiation; $\varepsilon$ is the long wave emissivity of the surface; and $\Delta R$ is the difference between the incident long wave radiation and the radiation emitted from the surface.

The general solution of the one dimensional heat conduction equation (assuming $T$ is finite when $x \rightarrow \infty$ ) may be written as,

$$
T_{(x, t)}=A_{0} \sum_{m=1}^{\omega} A_{m} \exp \left[i\left(m \omega t+\delta_{m} x\right)\right]
$$

where $\delta_{m}=m^{1 / 2} \alpha(1-i) ; \quad \alpha=\left(\omega \rho c_{h} / 2 k\right)^{1 / 2} ; c_{h}$ is the specific heat capacity of the material; $\rho$ is the density of the material, and $\omega=2 \pi / T$. Equation (8) gives the dependence of material temperature with thickness on the periodic variation of temperature at the surface [1]. $T_{A}$ can be expressed as Fourier series,

$$
\begin{aligned}
T_{s a} & =a_{0}+\sum_{m=0}^{\infty}\left(a_{m 1} \cos (m \omega t)+a_{m 2} \sin (m \omega t)\right) \\
& =a_{0}+\sum_{m=1}^{\infty}\left(a _ { m } \operatorname { e x p } \left(i\left(m \omega t-\delta_{m}\right)\right.\right.
\end{aligned}
$$

Substituting for $T_{(x, t)}$ from Equation (4) and for $T_{s a}$ from Equation (5) into Equation (2) and considering the real part,

$$
\begin{aligned}
T_{(x, t)}= & a_{0}+\sum_{m=1}^{\infty} B_{m} \exp \left(-m^{1 / 2} \alpha x\right) \\
& \cdot \cos \left(m \omega t-m^{1 / 2} \alpha x-\delta_{m}-\beta_{m}\right)
\end{aligned}
$$

where

$$
\begin{aligned}
& B_{m}=a_{m}\left(\left(1+m^{1 / 2} \mu\right)^{2}+m \mu^{2}\right)^{-1 / 2}, \\
& \mu=\frac{k a}{h}=\frac{\left(k \omega p \frac{c}{2}\right)^{1 / 2}}{h}, \\
& B_{m}=\tan ^{-1}\left(m^{1 / 2} \frac{\mu}{\left(1+m^{1 / 2} \mu\right)}\right) .
\end{aligned}
$$

and $a_{0}$ represents the average daily material temperature [1]. The daily temperature variation at different depths of the material is given by Equation (6) with $\beta_{m}=0, \omega=$ $2 \pi / 24 \mathrm{hr}, B_{m}=a_{m}$. The equation above is modified to obtain the following convenient form,

$$
T_{(x, t)}=T_{m}-A_{s} \exp (-\alpha x) \cos \left[\omega\left\{\left(t-t_{0}\right)-\frac{\alpha x}{\omega}\right\}\right]
$$

where $A_{s}$ is the daily temperature amplitude at the surface of the sample, i.e. at $x=0, t$ is the time of the day in hours, $x$ is the coordinate through the thickness of thesample, $t_{0}$ is the time of minimum temperature at the surface in hours, $\alpha$ is the thermal absorptivity $\left(\mathrm{m}^{-1}\right) \cdot T_{m}$ is calculated from the hourly surface temperature average $T_{h s s}(\mathrm{C})$ as 


$$
T_{m}=\sum_{m=1}^{24}\left(T_{h s s} / 24\right)
$$

Thus, on a 24 hour period, Equation (7) takes the form,

$$
\begin{aligned}
T_{(x, t)}= & T_{m}-A_{s} \exp (-\alpha x) \\
& \left.\cdot \cos \left[(2 \pi / 24)\left\{\left(t-t_{0}\right)-12 \alpha x / \pi\right\}\right)\right]
\end{aligned}
$$

The measurement of the thermal conductivity $k$, density $\rho$, and specific heat capacity $c$, of any material enable the determination of the value of thermal diffusivity $\lambda$, of the material using Equations (10)-(12),

$$
\lambda=k /(\rho c)
$$

The thermal diffusivity $\lambda$ is then used to calculate the thermal absorptivity, $\alpha$ from,

$$
\alpha=[\omega / 2 \lambda]^{1 / 2}
$$

The reciprocal of thermal conductivity gives the thermal resistivity, usually measured in Kelvin-meters per Watt $\left(\mathrm{Km} \cdot \mathrm{W}^{-1}\right)$,

$$
R=1 / k
$$

where $R$ is the thermal resistivity, $k$ is thermal conductivity. When dealing with a known amount of material, its thermal conductance and the reciprocal property, thermal resistance can be described.

When the mean value of absorptivity is substituted into Equation (9) it takes the form,

$$
\begin{aligned}
T_{(x, t)}= & T_{m}-A_{s} \exp (-50.963 x) \\
& \left.\cdot \cos \left[(2 \pi / 24)\left\{\left(t-t_{0}\right)-611.556 x / \pi\right\}\right)\right] \\
T_{(x, t)}= & T_{m}-A_{s} \exp (-43.098 x) \\
& \left.\cdot \cos \left[(2 \pi / 24)\left\{\left(t-t_{0}\right)-517.176 x / \pi\right\}\right)\right]
\end{aligned}
$$

\section{Results and Discussion}

The results obtainedusing our model is shown on Figures 1-4. We have also compared our results with the values reported by other researchers for other heat insulating materials. The density and thermal conductivity values obtained in this investigation are within the range

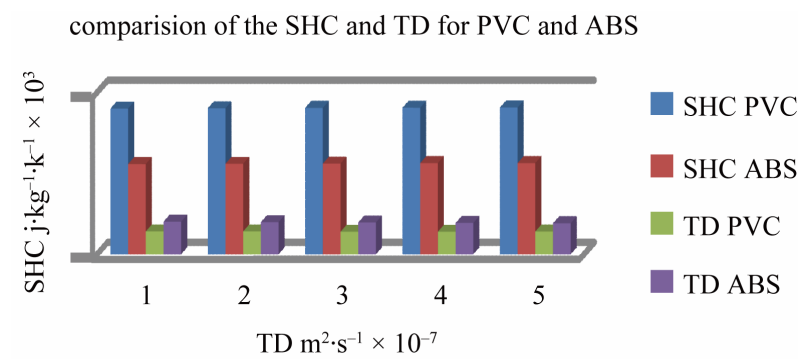

Figure 1. There is sharp decrease in the thermal diffusivity of both asbestos and PVC ceiling sheet as the specific heat capacity increases.

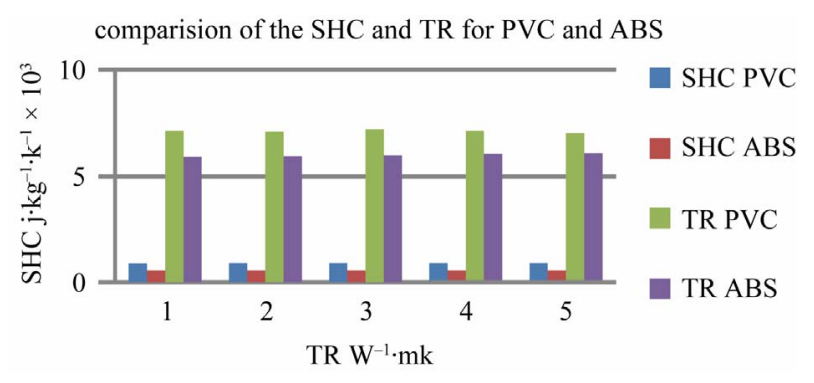

Figure 2. The Thermal resistivity for both PVC and asbestos shows remarkable increase as the SHC decreases gradually.

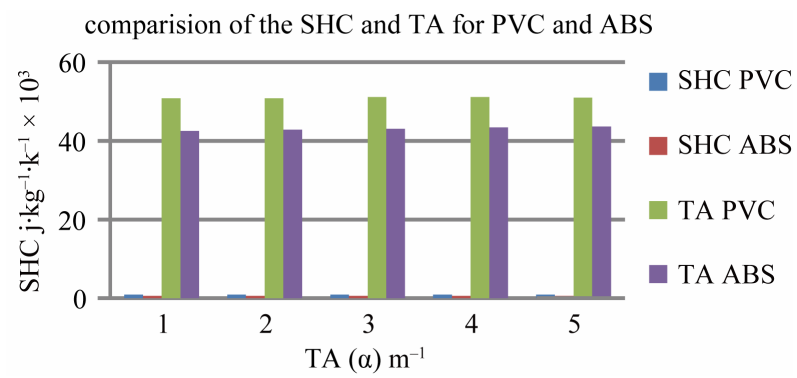

Figure 3. This shows that the SHC decreases as the thermal absorptivity (TA) of both materials increases, this shows that both materials are good absorbers of heat, making them a good choice for indoor cooling materials.

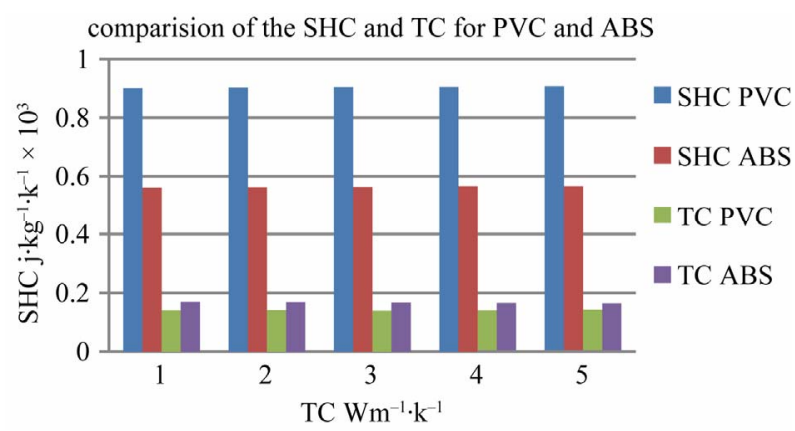

Figure 4. Shows that there is a gradual decrease in thermal conductivity in asbestos and PVC as the SHC increases.

of values of other commonly used wood based insulators given in references $[1,5,8]$ and also on Table 1.

Thermal resistivity, a reciprocal of thermal conductivity is another important thermal property of any construction material, it is the resistance of a material to heat flow irrespective of its thickness. The thermal resistivity for both PVC and Asbestos shows remarkable increase as the SHC decreasesgradually, while a corresponding decrease is also observed for the SHC for both materials as the TA increasesas shown in Figures 2 and 3. This shows that both materials are good walling materials especially in tropical countries. The results also show that the mean values for the thermal resistivity of asbestos ceiling sheet and $\mathrm{PVC}$ ceiling sheetis $6.003 \pm 0.068 \mathrm{~W}^{-1} \cdot \mathrm{m}$ and $7.123 \pm$ 
Table 1. Density and thermal conductivity of solids (At room temperature) [1,7].

\begin{tabular}{ccc}
\hline Material & Density $(\rho)\left(\mathrm{kg} \cdot \mathrm{m}^{-3}\right)$ & $\begin{array}{c}\text { Thermal condutivity } \\
\mathrm{k}\left(\mathrm{Wm}^{-1} \mathrm{k}^{-1}\right)\end{array}$ \\
\hline Oak wood & 770 & 0.160 \\
Pine wood & 570 & 0.138 \\
Pine fiber board & 256 & 0.052 \\
Brick building & 2300 & 0.600 \\
Coconut palm & 597 & 0.121 \\
Siporex board & 550 & 0.120 \\
Thermalite board & 753 & 0.190 \\
Wood block & 800 & 0.160 \\
Light plaster & 600 & 0.160 \\
Fibre board & 300 & 0.06 \\
\hline
\end{tabular}

$0.050 \mathrm{~W}^{-1} \cdot \mathrm{mk} \cdot \mathrm{W}^{-1}$, respectively. This is within the ranges of value $8.2908 \pm 0.1367 \mathrm{~W}^{-1} \cdot \mathrm{mk}$ as reported in references $[1,8]$. The result also indicates that the specific heat capacity value for PVC and asbestos ceiling sheet $(0.904$ $\pm 0.002) \times 10^{3} \mathrm{~J}^{\mathrm{kg}} \mathrm{kg}^{-1} \cdot \mathrm{k}^{-1}$ and $(0.564 \pm 0.0022) \times 10^{3}$ $\mathrm{J} \cdot \mathrm{kg}^{-1} \cdot \mathrm{k}^{-1}$, respectively, are within the range of values $(0.837-1.884) \times 10^{3} \mathrm{~J} \cdot \mathrm{kg}^{-1} \cdot \mathrm{K}^{-1}$ and $(1.198 \pm 0.006) \times$ $10^{3} \mathrm{~J} \cdot \mathrm{kg}^{-1} \cdot \mathrm{K}^{-1}$ for some commonly used building materials including wood-based insulating materials $[1,8]$.

Considering the above and the fact that thermal diffusivity of a material depends on the values of its thermal conductivity, density and specific heat capacity while thermal absorptivity is a function of thermal diffusivity, it therefore follows that $(0.196 \pm 0.0034) \times 10^{-7} \mathrm{~m}^{2} \cdot \mathrm{s}^{-1}$ and $43.098 \pm 0.38 \mathrm{~m}^{-1}$ recorded as the values of thermal diffusivity and thermal absorptivity of asbestos ceiling sheet and $50.963 \pm 0.16 \mathrm{~m}^{-1}$ and $(0.140 \pm 0.009) \times 10^{-7} \mathrm{~m}^{2} \cdot \mathrm{s}^{-1}$ recorded as the values of thermal absorptivity and thermal diffusivity of polyvinyl chloride (PVC) ceiling sheet favours them as good thermal insulating material.

\section{Conclusion}

The results obtained in this study have shown that both PVC and asbestos ceiling sheet has low density, low thermal conductivity and high thermal resistivity which compared favorably with those of other good thermal insulators already in use as thermal insulators in building design $[1,5,7,8]$. Also the value of the thermal resistivity obtained correlate well with the experimental data [3]. This type of insulators may be used in a building not only to reduce the thermal gain in summer but also to reduce the winter losses, thereby decreasing the energy consumption for heating or cooling of the interior space in a building. In view of the above comparison, PVC ceiling coupled with its physical appearance, strength, chemical resistance, fire resistance, maintenance-free and freedom from toxicity, odor, and taste may be a better material for thermal design application. Further research in the electrical properties of PVC and asbestos ceiling sheet should be undertaken and compared with other roofing materials like coconut palm, zinc, aluminum, and pin fiber board.

\section{REFERENCES}

[1] S. E. Etuk, L. E. Akpabio and K. E. Akpabio, "Determination of the Thermal Propertieies of Cocos Nucifera Trunk for Predicting Temperature Variation with Its Thickness," The Arabian Journal for Science and Engineering, Vol. 30, No. 1A, pp. 121-126.

[2] B. Y. Lattimer and J. Ouellette, "Properties of Composite Materials for Thermal Analysis Involving Fires," Composites: Part A, Vol. 37, No. 7, 2006, pp. 1068-1081. doi:10.1016/j.compositesa.2005.01.029

[3] C. Michels, R. Lamberts and S. Guths, "Theoretical/Experimental Comparison of Heat Flux Reduction in Roofs Achieved through the Use of Reflective Thermal Insulators," Energy and Buildings, Vol. 40, No. 4, 2008, pp. 438-444. doi:10.1016/j.enbuild.2007.03.012

[4] J. S. Pastuszka, "Emission of Airborne Fibers from Mechanically Impacted Asbestoscement Sheets and Concentration of Fibrous Aerosol in the Home Environment in Upper Silesia, Poland," Journal of Hazardous Materials, Vol. 162, No. 2-3, 2009, pp. 1171-1177. doi:10.1016/j.jhazmat.2008.06.045

[5] I. U. S. Demirdag, "Investigation of the Relation between the Specific Heat Capacity and Material Properties of Some Natural Building and Facing Stones," International Journal of Rock Mechanics \& Mining Sciences, Vol. 43, No. 5, 2006, pp. 831-835. doi:10.1016/j.ijrmms.2005.12.003

[6] S. X. Xua, Y. Lia and Y. P. Feng, "Study of Temperature Profile and Specific Heat Capacity in Temperature Modulated DSC with a Low Sample Heat Diffusivity," Thermochimica Acta, Vol. 360, No. 2, 2000, pp. 131-140. doi:10.1016/S0040-6031(00)00564-5

[7] S. Zhua, C. Lib, C. H. Su, B. Lin, H. Ban, R. N. Scripa and S. L. Lehoczky, "Thermal Diffusivity, Thermal Conductivity, and Specific Heat Capacity Measurements of Molten Tellurium," Journal of Crystal Growth, Vol. 250, No. 1-2, 2003, pp. 269-273.

doi:10.1016/S0022-0248(02)02250-9

[8] Y. Zhang, K. Lin, Q. Zhang and H. Di, "Ideal Thermophysical Properties for Free-Cooling (or Heating) Buildings with Constant Thermal Physical Property Material," Energy and Buildings, Vol. 38, No. 10, 2006, pp. 11641170. doi:10.1016/j.enbuild.2006.01.008

[9] K. J. Kontoleon and D. K. Bikas, "The Effect of South Wall's Outdoor Absorption Coefficient on Time Lag, Decrement Factor and Temperature Variations," Energy and Buildings, Vol. 39, No. 9, 2007, pp. 1011-1018. doi:10.1016/j.enbuild.2006.11.006 
[10] M. Wang, J. He, J. Yu and N. Pan, "Lattice Boltzmann Modeling of the Effective Thermal Conductivity for Fibrous Material," International Journal of Thermal Sci- ences, Vol. 46, No. 9, 2007, pp. 848-855.

doi:10.1016/j.ijthermalsci.2006.11.006 